\title{
Field-measured drag area is a key correlate of level cycling time trial performance
}

James E Peterman, Allen C Lim, Ryan Ignatz, Andrew G Edwards, William C Byrnes

Drag area $\left(A_{d}\right)$ is a primary factor determining aerodynamic resistance during level cycling and is therefore a key determinant of level time trial performance. However, $A_{d}$ has traditionally been difficult to measure. Our purpose was to determine the value of adding field-measured $A_{d}$ as a correlate of level cycling time trial performance. In the field, 19 male cyclists performed a level $(22.1 \mathrm{~km})$ time trial. Separately, field-determined $A_{d}$ and rolling resistance were calculated for subjects along with projected frontal area assessed directly $\left(A_{p}\right)$ and indirectly $\left(\right.$ Est $\left.A_{p}\right)$. Also, a graded exercise test was performed to determine $\mathrm{VO}_{2}$ peak, lactate threshold (LT), and economy. $\mathrm{VO}_{2}$ peak $\left(\mathrm{I} \cdot \mathrm{min}^{-1}\right)$ and power at LT were significantly correlated to power measured during the time trial $(r=0.83$ and 0.69 , respectively) but were not significantly correlated to performance time ( $r=-0.42$ and $-0.45)$. The correlation with performance time improved significantly $(p<0.05)$ when these variables were normalized to $A_{d}$. Of note, $A_{d}$ alone was better correlated to performance time $(r=0.85, p<0.001)$ than any combination of non-normalized physiological measure. The best correlate with performance time was field-measured power output during the time trial normalized to $A_{d}(r=-0.92)$. $A_{p}$ only accounted for $54 \%$ of the variability in $A_{d}$. Accordingly, the correlation to performance time was significantly lower using power normalized to $A_{p}(r=-0.75)$ or Est $A_{p}(r=-0.71)$. In conclusion, unless normalized to $A_{d}$, level time trial performance in the field was not highly correlated to common laboratory measures. Furthermore, our field-measured $A_{d}$ is easy to determine and was the single best predictor of level time trial performance. [b] 
2 Authors: James E. Peterman ${ }^{1}$, Allen C. Lim ${ }^{1}$, Ryan I. Ignatz ${ }^{1}$, Andrew G. Edwards ${ }^{1}$, William C.

3 Byrnes $^{1}$

$4{ }^{1}$ Department of Integrative Physiology, University of Colorado Boulder, Boulder, CO, USA

5

6 Corresponding Author:

7 William C. Byrnes

8 Department of Integrative Physiology

9 University of Colorado at Boulder

101725 Pleasant St., 354 UCB

11 Boulder, CO 80309

12 Telephone: 303 492-5301

13 Fax: 303 492-4009

14 E-mail: Byrnes@Colorado.edu

19 Running Title: Correlates of Time Trial Performance 


\section{Abstract}

21 Drag area $\left(\mathrm{A}_{\mathrm{d}}\right)$ is a primary factor determining aerodynamic resistance during level cycling and

22 is therefore a key determinant of level time trial performance. However, $\mathrm{A}_{\mathrm{d}}$ has traditionally been

23 difficult to measure. Our purpose was to determine the value of adding field-measured $A_{d}$ as a

24 correlate of level cycling time trial performance. In the field, 19 male cyclists performed a level

$25(22.1 \mathrm{~km})$ time trial. Separately, field-determined $\mathrm{A}_{\mathrm{d}}$ and rolling resistance were calculated for

26 subjects along with projected frontal area assessed directly $\left(\mathrm{A}_{\mathrm{P}}\right)$ and indirectly $\left(\right.$ Est $\left.\mathrm{A}_{\mathrm{P}}\right)$. Also, a

27 graded exercise test was performed to determine $\mathrm{VO}_{2}$ peak, lactate threshold (LT), and economy.

$28 \mathrm{VO}_{2}$ peak $\left(1 \cdot \mathrm{min}^{-1}\right)$ and power at $\mathrm{LT}$ were significantly correlated to power measured during the

29 time trial $(\mathrm{r}=0.83$ and 0.69 , respectively) but were not significantly correlated to performance

30 time $(\mathrm{r}=-0.42$ and -0.45$)$. The correlation with performance time improved significantly

$31(p<0.05)$ when these variables were normalized to $A_{d}$. Of note, $A_{d}$ alone was better correlated to

32 performance time $(\mathrm{r}=0.85, \mathrm{p}<0.001)$ than any combination of non-normalized physiological

33 measure. The best correlate with performance time was field-measured power output during the

34 time trial normalized to $A_{d}(r=-0.92)$. $A_{P}$ only accounted for $54 \%$ of the variability in $A_{d}$.

35 Accordingly, the correlation to performance time was significantly lower using power

36 normalized to $A_{P}(r=-0.75)$ or Est $A_{P}(r=-0.71)$. In conclusion, unless normalized to $A_{d}$, level

37 time trial performance in the field was not highly correlated to common laboratory measures.

38 Furthermore, our field-measured $A_{d}$ is easy to determine and was the single best predictor of

39 level time trial performance. 


\section{Introduction}

A cyclist's ability to produce and sustain mechanical power output is highly dependent upon physiological characteristics, particularly $\dot{\mathrm{VO}}_{2}$ max, lactate threshold (LT), and economy (Coyle et al., 1988; Coyle 1995). In the laboratory, where resistive forces are controlled or minimized, these physiological factors have been successfully used to predict simulated time trial performance (Coyle et al., 1988; Loftin \& Warren, 1994; Coyle, 1995; Bishop et al., 2000; Bentley et al., 2001; Lamberts et al., 2012; ). However, in the field when cycling on level terrain at constant velocities $\left(\left(>40 \mathrm{~km} \cdot \mathrm{hr}^{-1}\right)\right.$, more than $90 \%$ of the total resistance $\left(\mathrm{R}_{\text {TOT }}\right)$ impeding the forward motion of a bicycle-rider system is determined by aerodynamic resistance $\left(\mathrm{R}_{\mathrm{a}}\right)(\mathrm{Pugh}$, 1974; di Prampero et al., 1979; Martin et al., 1988; Olds \& Olive, 1999). Thus, measures of a cyclist's ability to supply mechanical power do not always predict performance time in time trial racing (Hoogeveen \& Schep, 1997; Balmer, Davison \& Bird, 2000). For example, Balmer et al. (2000) demonstrated that while peak mechanical power output assessed during a graded exercise stress test does correlate highly $(\mathrm{r}=0.99, \mathrm{p}<0.001)$ with average mechanical power output during a $16.1 \mathrm{~km}$ field time trial, neither the laboratory peak mechanical power output nor the average mechanical power output during the time trial correlated well with performance time $(r=0.46, p$ $>0.05)$. One possible explanation for these results is that the resistance impeding the forward motion faced by competitive cyclists is variable enough that mechanical power output alone may not predict performance (Jeukendrup \& Martin, 2001).

Measuring the aerodynamic resistance force $\left(\mathrm{R}_{\mathrm{a}}\right)$ during cycling can be complex. Direct measures include wind-tunnel tests (Davies, 1980; Kyle, 1991; Martin et al., 1998), motorized towing (di Prampero et al., 1979; Capelli et al., 1993), and coasting deceleration methods (de Groot, Sargeant \& Geysel, 1995; Candau et al., 1999). Even though these direct measurements 
63 are accurate, they are impractical for most researchers and practitioners. For example, wind-

64 tunnel testing facilities are inaccessible and costly. In addition, during wind tunnel testing, the

65 bikes are not physically moving through the air and the pedaling motion introduces noise in the

66 force measurement system during each pedal stroke. Motorized towing and coasting

67 deceleration methods are also elaborate in their setup and execution meaning they are not an 68 ideal substitute to a wind tunnel.

69 Because measuring the aerodynamic resistance force can be complex, it is sometimes

70 assumed to be directly proportional to measures or estimates of the projected frontal area $\left(A_{P}\right)$ of

71 the bicycle and rider (di Prampero et al., 1979; de Groot, Sargeant \& Geysel, 1995; Olds \&

72 Olive, 1999; Heil, 2001; Anton et al., 2007). This assumes, though, that between individuals,

73 aerodynamic resistance changes predictably with changes in $A_{P}$. However, evidence exists to the

74 contrary. Previous research shows a lack of proportionality between an individual's measured

$75 A_{\mathrm{P}}$ and aerodynamic resistance (Kyle, 1991; de Groot, Sargeant \& Geysel, 1995). This

76 discrepancy must be due to variability in the coefficient of drag $\left(\mathrm{C}_{\mathrm{d}}\right.$, see equation 2$)$, which is

77 influenced by the shape of the bicycle and rider, varies greatly between individuals, and does not

78 change proportionally with changes in projected frontal area (Debraux et al., 2011).

Recently, it has been demonstrated that measuring mechanical power output and speed in

80 the field with cycle mounted power meters is a viable and accessible technique for determining

81 an individual's aerodynamic and rolling resistances (Martin et al., 2006; Debraux et al., 2011;

82 Lim et al., 2011). This technique, in combination with standard physiological profiling, could

83 improve our ability to predict field performance since it has been argued that physical factors

84 resisting forward motion play a larger role in performance outcome than physiological variables

85 (Jeukendrup \& Martin, 2001). Anton et al. (2007) have previously shown that projected frontal 
86

87 88

91

area alone is correlated to performance time during a level time trial $(r=-0.73)$. However, their estimated frontal area did not improve the prediction of level time trial performance compared to just maximal mechanical power output measured in the lab. As described above, $A_{P}$ is not directly proportional to aerodynamic resistance. Thus, the aerodynamic characteristic of a cyclist (drag area $\left(A_{d}\right)$ ), which includes both $A_{P}$ and $C_{d}$, may provide a better correlation for time trial performance.

Accordingly, the purpose of this study was to quantify physiological determinants of endurance performance in conjunction with physical factors that contribute to resistance during cycling. Correlations between the various determinants/factors and level time trial performance were then compared. We hypothesized a cyclist's physiological capacity or average power output would not predict level time trial performance time unless normalized to some representation of aerodynamic resistance. Additionally, we hypothesized that estimates of aerodynamic resistance, such as direct and indirect assessments of projected frontal area, would not correlate to performance as highly as the actual aerodynamic characteristic of the cyclist.

\section{Methods}

\section{Subjects:}

Nineteen competitive male cyclists volunteered for this study. All subjects were licensed cyclists (United States Cycling Federation Category Pro/1/2 Road or Pro/Expert MTB) living, training, and racing in the Colorado, USA area for a minimum of two months. All tests were performed during the height of the local competitive cycling season. Descriptive characteristics of our nineteen subjects and the results from the laboratory testing are presented in Table 1. All subjects were informed of the risks involved with participation in the study and gave written 
109 informed consent before participating. The Human Research Committee at the University of

110 Colorado Boulder approved the protocol used for this study (reference number 0600.20).

111 Power Measuring Devices and Calibration:

112 All subjects utilized a rear hub power meter (CycleOps PowerTap, Madison, WI, USA)

113 set to record external power output, ground velocity, cadence, and time measured at a frequency

114 of $61 \mathrm{~Hz}$ with data averaged and recorded in epochs of 1.26 seconds for all variables. Heart rate

115 was recorded using a CycleOps heart rate monitor chest strap that transmitted to the power meter

116 computer. Nineteen distinct power meters were used throughout the study, one for each subject.

117 Each subject used the same power meter for the time trial, laboratory testing, and

118 aerodynamic/rolling resistance measures. Prior to commencing trials, all units used during

119 testing were calibrated against a zero torque reference while pedals were stationary and unloaded

120 as directed by the manufacturer.

121 Laboratory Measures and Protocol:

122 Laboratory measured endurance performance predictors including peak oxygen

123 consumption ( $\mathrm{VO}_{2}$ peak), lactate threshold (LT), and economy (Watts $1 \mathrm{O}_{2}^{-1} \cdot \mathrm{min}^{-1}$ at LT) were

124 measured during a graded exercise test conducted within three days of the subject's time trial.

125 Each test was performed on the subject's personal road bicycle attached to an electronically

126 braked trainer (CompuTrainer ${ }^{\circledR}$, Seattle, WA, USA) with power measured using the rear hub

127 power meter loaned to the subject at the beginning of the study. The protocol began at a power

128 output between 100 to 150 watts and increased by approximately 30 watts every 4 minutes until

129 volitional fatigue. All tests were conducted at an altitude of 1,625 meters (5,330 feet) with an

130 average barometric pressure, temperature, and humidity of $630.5 \pm 3.4 \mathrm{mmHg}, 22.9 \pm 1.4{ }^{\circ} \mathrm{C}$, 
131 and $37.1 \pm 6.9 \%$, respectively. Additionally, a fan was used to cool subjects throughout each

132 exercise stress test.

133 Oxygen consumption and carbon dioxide production were averaged every 15 seconds

134 through computer assisted indirect calorimetry using Parvomedics software and hardware to

135 integrate input from a Validyne pressure tranducer and Perkin Elmer mass spectrometer. The

136 pressure transducer was linked to a Hans Rudolph pneumotach measuring inspired ventilation

137 and the Perkin Elmer mass spectrometer sampled from a 4-liter mixing chamber. Calibration

138 procedures are summarized in Appendix A.

139 Peak oxygen consumption was defined as the highest rate of oxygen consumption for a

140 sampling interval of one minute during the graded exercise stress test. Subjects were vigorously

141 encouraged to give a maximal effort and in all cases exceeded a respiratory exchange ratio of

1421.15 and a blood lactate of $7 \mathrm{mM}$ at volitional exhaustion. For the measure of economy, only the

143 oxygen consumed over the last two minutes of each 4-minute stage was used to ensure steady

144 state measures. Economy was measured as the ratio between power output and oxygen

145 consumption (Watts $\cdot 1 \mathrm{O}_{2}^{-1}$ ) at the lactate threshold from a regression of the oxygen consumption

146 versus power relationship. In all subjects, the relationship between oxygen consumption and

147 power output was linear $(r>0.99)$ through the penultimate stage.

148 Blood lactate concentration was measured at rest and over the last minute of each 4-

149 minute stage. For each sample, approximately $50 \mu 1$ of blood was drawn via finger pricks into a

$15075 \mu 1$ capillary tube. Twenty-five $\mu 1$ was then mixed with a "cocktail" containing $50 \mu 1$ of a

151 buffer, lysing (Triton XL-100), and anti-glycolytic (sodium fluoride) solution. Lactate was

152 finally analyzed using a YSI 2300 lactate analyzer (Yellow Springs, Ohio, USA). Before each

153 test, the lactate analyzer was calibrated against a known standard, and re-calibrated every 15 
154 minutes. The lactate threshold was defined as a point $1 \mathrm{mM}$ above a baseline that included

155 resting lactate (Coyle et al., 1988). This process includes some subjective interpretation in

156 determining the baseline values leaving room for potential human error. Thus, the average value

157 for these points determined from eight independent observers was used in data analysis. No

158 significant difference was found between observers.

159 Heart Rate during laboratory testing was measured using radio telemetry (Polar ${ }^{\circledR}$, Lake

160 Success, NY, USA) each minute while perceived exertion was measured using the Borg 6-20

161 scale 3 minutes into each stage. Within two days of the laboratory test, body composition was

162 assessed using dual energy x-ray absorbtiometry (GE LUNAR DXA system, Fairfield, CT, 163 USA).

164 Time Trial:

165 The level time trial was conducted over two laps of a four-corner loop in Hygiene,

166 Colorado. The total distance of the time trial was $22.1 \mathrm{~km}$. Over the course of each lap, subjects

167 gained and lost 79 meters of elevation for a net elevation gain of 0 meters. The layout of the

168 course allowed the subjects to ride continuously with no stop signs or traffic lights impeding

169 their effort. Subjects were allowed to utilize time trial bicycles equipped with time trial bars and

170 an aerodynamic front wheel. Six subjects rode their standard road bike with no additional

171 aerodynamic equipment. Another four subjects rode their standard road bike equipped with

172 aerodynamic handlebars. The other nine subjects utilized a time trial bicycle equipped with

173 aerodynamic handlebars with an aerodynamic deep dish or three-spoked front wheel.

174 Within two weeks prior to the time trial, subjects were asked to pre-ride the course to

175 familiarize them with the route. All subjects had previous experience training on the selected

176 course. Directly prior to the time trial, subjects performed their personal pre-competition warm- 
177 up. At this time, tires were inflated to 8.3 bar with the riders off the bicycle. Immediately before

178 the time trial, the subject's individual mass $\left(\mathrm{M}_{R}\right)$ and bicycle rider system mass $\left(\mathrm{M}_{\mathrm{BRS}}\right)$ were

179 measured using an electronic scale previously calibrated against a laboratory balance scale

180 (Detecto Scales, Webb City, MO, USA). At the start line, the on-board computers were cleared

181 and the power meters calibrated against a zero load. During the time trial, subjects were blinded

182 from viewing their power output but allowed to view speed, time, distance, cadence, and heart

183 rate. In addition to the time measured by the on-board computer, performance time was also

184 measured using an external stopwatch.

185 All time trials were held between 9 and $11 \mathrm{am}$. Air density was calculated from measures

186 of ambient temperature, station pressure, and relative humidity collected with a Vantage Pro

187 model weather instrument (Digital Instruments, Enterprise, OR, USA). Though an attempt was

188 made to schedule as many subjects as possible on the same day to control for wind,

189 environmental conditions, and the competitive atmosphere, a total of ten separate time trials were

190 performed with seven subjects performing the time trials alone and the others on one of three

191 occasions. On days in which multiple subjects performed the time trial, enough time was given

192 between the start of each subject so that subjects were not able to pace or draft off each other

193 during the trial. During these separate occasions, the time trials were allowed to proceed as long

194 as the wind did not exceed a 3 or a "gentle breeze" on the Beaufort Wind Scale. This is

195 equivalent to a wind speed less than $19 \mathrm{~km} \cdot \mathrm{hr}^{-1}$ characterized by surroundings in which smoke

196 rises vertically (0) to a wind velocity were leaves and small twigs constantly move (3).

197 Data Reduction and Analysis:

198 Immediately after the time trial, data collected from the CycleOps power meter and heart

199 rate monitor was downloaded from the onboard computer to an Apple G4 computer. 
200 Downloaded data included time, power output, speed, cadence, and heart rate in 1.26-second 201 intervals. Using Power Coach ${ }^{\mathrm{TM}}$ (Kochli Sport, Sonvilier, Switzerland) software operated by 202 Apple G4 computers, the performance time measured by the external stopwatch was located on 203 the data and isolated. The distance from this isolated data was then checked to ensure that it 204 matched the actual distance of the course. The data isolated in this manner did not vary by more 205 than 50 meters $(7.26 \pm 4.26 \mathrm{sec})$ from the actual distance of the course. Each line of data was 206 also checked for any potential recording problems with any erroneous (loss of signal or supra207 physiological) data interpolated between the adjacent data points. On average, approximately 208 four seconds of data were interpolated in any given time trial (range $=0$ to 24 seconds), with 209 never more than 2 erroneous data points occurring in sequence. Finally, the statistics of interest 210 were calculated using specific code written for Matlab ${ }_{\circledast}$ (Mathworks Inc., Berkeley, CA, USA). 211 Field Measured Aerodynamic and Rolling Resistance Profiling:

212 Within three weeks of the time trial, aerodynamic and rolling resistances were

213 determined from field measures of power and velocity (Edwards \& Byrnes, 2007; Lim et al.

214 2011). Using the methodology described by di Prampero et al. (1979), drag area $\left(A_{d}\right)$ and rolling 215 resistance $\left(R_{r}\right)$ were calculated for each subject (see Appendix A).

216 Projected Frontal Area

217 Projected frontal area was determined based on the recommendations of Olds and Olive 218 (1999). Digital photographs (Nikon Cool Pix 4300, Melville, NY) of the subjects were taken 219 while subjects sat in a riding position on the bicycle they used during the time trial, which was 220 mounted on a stationary trainer. Photographs were analyzed using NIH Image 1.62 software. 221 This software, after calibration against a known distance or area, automatically calculates the 222 area of a given tracing. Projected frontal area was calculated from tracings of the subject's body 
223 and helmet only with the bicycle excluded. In addition to actual measures of projected frontal

224 area, estimates of projected frontal area were also made. Numerous equations have been

225 provided in the literature to either predict or account for some aspect of the aerodynamic drag or

226 frontal area of cyclists (Pugh, 1974; Davies, 1980; McLean, 1993; Olds, Norton \& Craig, 1993;

227 Olds et al., 1995; Heil, 2001; Heil, 2002). Some of the equations rely on the assumption that $A_{P}$ 228 is a constant fraction of body surface area (BSA), while others derive more complex algorithms 229 to predict $A_{P}$ based on various anthropometric qualities of a cyclist (i.e. height and weight). A 230 total of ten different equations from previous research (DuBois \& DuBois, 1916; Pugh, 1974;

231 Davies, 1980; McLean, 1993; Olds, Norton \& Craig, 1993; Olds et al., 1995; Heil, 2001) were 232 compared.

233 Statistical Analyses:

234 Bivariate correlations were performed to assess the relationship between physical,

235 physiological, and normalized variables to time and average power measured during the time 236 trial. In addition, stepwise multiple regressions were performed to locate the best single or 237 combination of variables predictive of time and average power output. Differences between 238 correlation coefficients were then located using the Hotelling test. The Pearson product-moment 239 correlation coefficients were used to determine the relationship between actual and predicted 240 values of $A_{p}$ and $A_{d}$. Repeated-measure ANOVAs were run to determine if mean differences 241 existed between actual and predicted values of Ap. If significance was found, the more 242 conservative Scheffe post-hoc test was used to determine which variables differed. Significance 243 for all calculations was set at $\mathrm{p}<0.05$. Descriptive data are reported as the mean, standard 244 deviation, minimum, and maximum. 


\section{Results}

The primary components of resistance during cycling are presented in Table 2 . Because the $A_{P}$ was calculated with the rider only while the $A_{d}$ was calculated for the entire bicycle and rider system, it would be technically incorrect to calculate a $C_{d}$ for the bicycle and rider system or rider alone. Still, dividing $A_{d}$ by the $A_{P}$ would give a estimated $C_{d}$ of $1.03 \pm 0.12$. A correlation of 0.735 was found between $A_{P}$ and $A_{d}$. No relationship, however, was found between $A_{P}$ and the $C_{d}(r=-.170, p=0.486)$. measured, $\dot{V} O_{2}$ peak $\left(1 \cdot \mathrm{min}^{-1}\right)(\mathrm{r}=0.83, \mathrm{p}<0.001)$, power at $\dot{V} \mathrm{O}_{2}$ peak $(\mathrm{r}=0.67, \mathrm{p}<0.001)$, and power at LT $(\mathrm{r}=0.69, \mathrm{p}<0.001)$ were significantly correlated to field-measured power output during the time trial. These physiological measures, however, were not strongly or significantly related to time trial performance time $\left(\dot{V} \mathrm{O}_{2}\right.$ peak $\mathrm{r}=-0.42, \mathrm{p}=0.08$; power at $\dot{V} \mathrm{O}_{2}$ peak $\mathrm{r}=$ $0.43, \mathrm{p}=0.07$; power at $\mathrm{LT} \mathrm{r}=-0.45, \mathrm{p}=0.06$ ). In addition, although significant, the fieldmeasured power output during the time trial was correlated to performance time with an r-value of only -0.59 . Thus, as hypothesized, non-normalized physiological measures were not strongly related to time trial performance time.

The correlation of physiological measures and performance time greatly increased when normalized to aerodynamics. When normalized to $A_{d}$, power at $\mathrm{VO}_{2}$ peak (watts $\left.\cdot \mathrm{m}^{-2}\right)(\mathrm{r}=-0.92$, $\mathrm{p}<0.001)$ and power at $\operatorname{LT}(\mathrm{r}=-0.85, \mathrm{p}<0.001)$ were better correlated to performance time (Fig. 1). Other normalized laboratory physiological performance measurements were either not significant or if significant were only moderately correlated. The correlation to performance time was best when mean field-measured power output was normalized to either $\mathrm{k}(\mathrm{r}=-0.92, \mathrm{p}<$ 
$2680.001)$ or $\mathrm{A}_{\mathrm{d}}(\mathrm{r}=-0.92, \mathrm{p}<0.001)$. Figure 2 displays the relationship between performance time 269 relative to the mean field-measured power output as well as mean field-measured power output 270 normalized to body mass, $A_{P}$, and $A_{d}$. Rolling resistance alone or when used to normalize power 271 or physiological measures was not related to performance time. Both $k(r=-0.32, p=0.18)$ and $A_{d}(r=-0.32, p=0.17)$ were not correlated to field273 measured power output during the time trial. However, both $\mathrm{k}(\mathrm{r}=0.85, \mathrm{p}<0.001)$ and $\mathrm{A}_{\mathrm{d}}(\mathrm{r}=$ $2740.85, \mathrm{p}<0.001)$ alone were significantly related to performance time. Although significant ( $\mathrm{p}=$ 275 0.04), measured $A_{P}$ alone had a lower correlation $(r=0.47)$ and no methods for determining Est $276 A_{P}$ correlated with performance time $(r=0.010$ to 0.099$)$. Furthermore, field-measured power 277 output normalized to $A_{P}$ was only modestly correlated to performance time $(r=-0.75)$. Assuming that all of the resistance faced by the cyclists during the time trial was due to 279 aerodynamic and rolling resistance, estimates of power for each component are given. 280 Aerodynamic power was calculated from the $\mathrm{k}$ measured for each subject's bicycle position 281 while rolling resistance was assumed to be the remainder of the power. During the time trial, 282 aerodynamic and rolling resistance accounted for $89.77 \%$ and $10.23 \%$ of the total power at $272 \pm$ 28323 and $31 \pm 12$ watts, respectively. Except for the Olds et al. (1995) and Heil (2001) methods ( $\mathrm{P}>0.999$ and 0.322, 285 respectively), the mean value for $A_{P}\left(0.338 \pm 0.049 \mathrm{~m}^{2}\right)$ was significantly over predicted by all 286 other estimations of $A_{P}$ as a percent of BSA ( $p<0.001$; Pugh (34), $\left.\mathrm{P}=0.011\right)$. The range for Est $287 \mathrm{~A}_{P}$ as a percent of BSA was $0.306 \pm 0.020 \mathrm{~m}^{2}$ to $0.495 \pm 0.032 \mathrm{~m}^{2}$. For predictions of $A_{P}$ based 288 on anthropometric algorithms, except for the Heil (2002) method ( $\mathrm{P}=0.983)$, all other methods 289 significantly $(\mathrm{p}<0.001)$ over predicted our digitized $A_{P}$. These Est $A_{P}$ ranged from $0.399 \pm$ 
$0.025 \mathrm{~m}^{2}$ to $0.550 \pm 0.028 \mathrm{~m}^{2}$. No correlation was found between total mass and $A_{P}(r=0.302, p$

$291=0.208)$.

292 Stepwise regression was also performed to predict time trial performance time and

293 power. In this multivariate analysis, the best correlates of level time were the mean field-

294 measured power to $A_{d}(r=-0.92, p<0.001, y=-0.53 x$ time trial power to drag area +2358.6$)$.

295 The correlation coefficient for this relationship was not significantly different from that for

296 power to $\mathrm{k}(\mathrm{r}=-0.92, \mathrm{p}<0.001)$, which indicates that variations in ambient air density between

297 the different time trial days was unlikely to have had much impact on performance time in our

298 group of subjects. If power at $\mathrm{VO}_{2}$ peak and LT are normalized to parameters that affect

299 resistance, the best correlate of performance time was power at $\dot{V} O_{2}$ peak normalized to $\mathrm{A}_{\mathrm{d}}(\mathrm{r}=-$

$3000.92, \mathrm{p}<0.001, \mathrm{y}=-0.48 \mathrm{x}$ power at $\dot{V} O_{2}$ peak to $\left.\mathrm{A}_{\mathrm{d}}+2394.8\right)$. This correlation was not

301 significantly different from that obtained using the mean field-measured power normalized to $A_{d}$

302 or k. For power output during the time trial, the best correlate from all the variables measured in

303 the laboratory is $V O_{2}$ peak $\left(1 \cdot \mathrm{min}^{-1}\right)\left(\mathrm{r}=0.83, \mathrm{p}<0.001, \mathrm{y}=54.67 \mathrm{x} \dot{V} O_{2}\right.$ peak +48.8$)$.

304

305 Discussion

306 As hypothesized, a cyclist's mean field-measured power output normalized to our field-

307 determined aerodynamic resistance (i.e., $\mathrm{k}$ or $\mathrm{A}_{\mathrm{d}}$ ) was the best correlate of level time trial

308 performance time $(\mathrm{r}=-0.92, \mathrm{p}<0.001)$. These results demonstrate and confirm that

309 aerodynamic resistance is the primary resistance that is faced when cycling on level terrain.

310 Accordingly, lab-measured physiological indices of performance (e.g. power at $\mathrm{VO}_{2}$ peak),

311 though significantly correlated to field-measured power output $(r=0.64)$, were not significantly

312 related to performance time $(r=-0.43)$, unless normalized to aerodynamic resistance $(r=-0.92)$. 
313 Of note, our field-determined drag area alone was the single best correlation with performance

314 time on the level $(\mathrm{r}=0.85, \mathrm{p}<0.001)$, confirming that aerodynamic resistance in our population

315 played the most significant role in level time trial performance. Further, our field-determined

316 drag area improved correlations to performance time better than either $A_{P}$ or Est $A_{P}$. In addition,

317 rolling resistance was not a distinguishing predictor of performance reflecting its smaller

318 contribution to the resistance to forward motion during cycling.

319 In agreement with Balmer et al. (2000), we found the majority of laboratory measures

320 were not significantly correlated to level time trial performance time. In contrast to our findings

321 though, a number of investigators have shown stronger correlations between laboratory measures

322 of performance and level time trial performance in the field (Hawley \& Noakes, 1992; Nichols,

323 Phares \& Buono, 1997; Smith, Dangelmaier \& Hill, 1999; Anton et al., 2007). It is likely that

324 these conflicting findings are due to differences in the subject populations recruited. For

325 example, in the study by Anton et al. (2007), the subject population had a relatively homogenous

326 frontal surface area $\left(0.35 \pm 0.02 \mathrm{~m}^{2}\right)$ and a relatively heterogeneous maximal mechanical power

327 output (490 \pm 56 Watts) compared to the subjects from our study $(0.34 \pm 0.05$ and $362 \pm 30$,

328 respectively). This homogeneity in frontal surface area likely resulted in a greater correlation

329 between laboratory measures and level time trial performance. Because level time trial

330 performance is essentially a balance between resistive forces (primarily aerodynamic resistance)

331 and propulsive forces (mechanical power output), homogeneity in one factor results in the other

332 heterogeneous factor having a greater correlation. Furthermore, it is our belief that correlations

333 in these previous studies would be stronger if the laboratory performance measures were

334 normalized to the subject's actual aerodynamic drag area. For instance, in our study, power at 
335 LT had a correlation of -0.45 with performance time but when this same laboratory measure was

336 normalized to $A_{d}$, the correlation became -0.85 .

337 Our finding that level time trial performance time is best predicted by normalizing field-

338 measured power output to either $\mathrm{k}$ or $\mathrm{A}_{\mathrm{d}}(\mathrm{r}=-0.92, \mathrm{p}<0.001)$, while perhaps self-evident,

339 underscores the significant absence of actual aerodynamic measures in studies attempting to

340 predict cycling time trial performance in the field. Martin et al. (2006) found measured

341 aerodynamic drag can be used to predict sprinting speed in cyclists. Our study furthers these

342 findings and is the first to highlight the importance of measured aerodynamics during longer

343 duration events at slower speeds compared to those seen during sprinting. In our study, the mean

344 field-measured power was significantly correlated to level time $(r=-0.59, p<0.01)$ but only

345 explained $35 \%$ of the variability in level time. When field-measured power was normalized to

346 aerodynamics though, $85 \%$ of the variability was explained highlighting that differences in

347 aerodynamics are a critical performance determinant.

348 We found aerodynamic drag alone represented as either $\mathrm{k}$ or $\mathrm{A}_{\mathrm{d}}$, was significantly

349 correlated to performance time $(r=0.85, p<0.001)$, explaining $72 \%$ of the variability in

350 performance time. The heterogeneous equipment and positions subjects used in the time trial

351 may have aided this finding. Out of our nineteen subjects, nine used time trial bicycles, four

352 used standard road bicycles with aerodynamic handlebars, and the remaining six used a standard

353 road bicycle with no specific aerodynamic equipment. However, while each group had

354 significantly different mean values for $A_{d}$, within the nine subjects using time trial bicycles, our

355 results were similar with mean field-measured power normalized to aerodynamics the single best

356 predictor of performance time $(\mathrm{r}=-0.88, \mathrm{p}<0.001)$, aerodynamics the next best predictor $(\mathrm{r}=$

$3570.72, \mathrm{p}<0.001)$, and field-measured power not predicting performance time $(\mathrm{r}=-0.33, \mathrm{p}>0.05)$. 
358 The range in $A_{d}$ between subjects riding a time trial bicycle $\left(0.258\right.$ to $\left.0.355 \mathrm{~m}^{2}\right)$ may have also

359 aided in this finding. This range in $A_{d}$ though, also highlights the variability that exists between

360 individuals with similar equipment and the importance of determining drag area to predict level

361 time trial performance.

362 Because aerodynamic drag has been difficult to measure in the past, many studies have

363 attempted to use estimates of the projected frontal area (Est $\left.A_{P}\right)$ or actual measures of projected

364 frontal area $\left(A_{P}\right)$ to represent aerodynamic drag $\left(A_{d}\right)$ (Swain, 1994; Anton et al., 2007).

365 Estimating $A_{d}$ in this manner assumes a constant coefficient of drag $\left(C_{d}\right)$, which along with $A_{P}$

366 makes up $A_{d}$. However, in the present study, $A_{P}$ only accounted for $54 \%$ of the variability in $A_{d}$.

367 This discrepancy is largely due to individual differences in $C_{d}$. Assuming a constant $C_{d}$ requires

368 that riders must be riding in the same environmental conditions while using the same bike,

369 geometry, clothing, and equipment. However, the range of $C_{d}$ values between our subjects

370 (0.823 to 1.262$)$ highlights the individual variability in this measure. Furthermore, in agreement

371 with previous work (Kyle, 1991; de Groot, Sargeant \& Geysel, 1995; Debraux et al., 2011), we

372 found no relationship between $A_{P}$ and $C_{d}(r=-0.17, p=0.49)$ demonstrating their independence

373 and individual importance in determining $A_{d}$. Accordingly, when normalizing field measured

374 power output during the time trial, we found that the correlation to performance time was

375 significantly lower using $A_{P}(r=-0.75)$ or Est $A_{P}(-0.71)$ compared to normalizing using our

376 field-determined $A_{d}(r=-0.92)$. Thus, actual projected frontal area or an estimate of projected

377 frontal area does not explain all of the variability in $A_{d}$ and when used to normalize power is not

378 necessarily better in the prediction of level time trial performance than $A_{d}$ alone $(r=-0.85)$.

379 The results from the present study suggest that field-testing with a power meter may be a

380 better alternative to traditional laboratory testing (i.e. $\mathrm{VO}_{2}$ peak, $\mathrm{LT}$, economy) for athletes and 
381 coaches wanting to predict time trial performance. The field-measured drag area in combination

382 with field-measured power output provided the best prediction of time trial performance

383 compared to any combination of laboratory testing. Furthermore, we demonstrate that

384 determining drag area does not need to be difficult. Our field-measured determination of drag

385 area was the single best predictor of time trial performance and requires only a power meter,

386 speedometer, and flat road making it far more economical than other tools (i.e. a wind tunnel).

387 Thus, athletes can easily quantify and improve performance in events like level time trials by

388 using our field-measured drag area technique to optimize the relationship between aerodynamic

389 resistance and power output.

390 In conclusion, to predict cycling performance in the field, a cyclist's ability to produce

391 power must be considered relative to the forces that resist forward motion. Accordingly, level

392 time trial performance is best predicted by normalizing the mean field-measured power output to

393 aerodynamic resistance per velocity squared $(\mathrm{k})$ or the drag area $\left(\mathrm{A}_{\mathrm{d}}\right)$. Despite the fact that

394 physiological variables are commonly thought of as the most important determinant of

395 performance, we found that alone, measures of aerodynamic resistance were better related to

396 level performance than $\mathrm{VO}_{2}$ peak, LT, or economy. Moreover, the use of projected frontal area

$397\left(\mathrm{~A}_{\mathrm{P}}\right)$ or estimates of projected frontal area $\left(\right.$ Est $\left.\mathrm{A}_{\mathrm{P}}\right)$ are not as accurate as directly measured $\mathrm{A}_{\mathrm{d}}$. 
1. Anton M, Izquierdo M, Ibanez J, Asiain X, Mendiguchia J, Gorostiaga E. 2007. Flat and uphill climb time trial performance prediction in elite amateur cyclists. International Journal of Sports Medicine. 28(4): 306-313.

2. Balmer J, Davison RC, Bird SR. 2000. Peak power predicts performance power during an outdoor 16.1-km cycling time trial. Medicine and Science in Sports and Exercise. 32:1485-1490.

3. Bentley DJ, McNaughton LR, Thompson D, Vleck VE, Batterham AM. 2001. Peak power output, the lactate threshold, and time trial performance in cyclists. Medicine and Science in Sports and Exercise. 33: 2077-2081.

4. Bertucci W, Duc S, Villerius V, Permin JN, Grappe F. 2005. Validity and realiability of the PowerTap mobile cycling powermeter when compared with the SRM device. International Journal of Sports Medicine. 26(10): 868-73.

5. Bishop D, Jenkins DG, McEniery M, Carey MF. 2000. Relationship between plasma lactate parameters and muscle characteristics in female cyclists. Medicine and Science in Sports and Exercise. 32: 1088-1093.

6. Candau R, Grappe F, Menard M, Barbier B, Millet GY, Hoffman MD, Belli AR, Rouillon JD. 1999. Simplified deceleration method for assessment of resistive forces in cycling. Medicine and Science in Sports and Exercise. 31(10): 1441-1447. cost and efficiency of riding aerodynamic bicycles. European Journal of Applied Physiology. 67: 144-149. 
8. Coyle EF. 1995. Integration of the physiological factors determining endurance performance ability. Exercise Sports Science Reviews. 23: 25-63.

9. Coyle EF, Coggan AR, Hopper MK, Walters TJ. 1988. Determinants of endurance in well-trained cyclists. Journal of Applied Physiology. 64: 2622-2630.

10. Davies C. 1980. Effect of air resistance on the metabolic cost and performance of cycling. European Journal of Applied Physiology. 45: 245-254.

11. Debraux P, Grappe F, Manolova AV, Bertucci W. 2011. Aerodynamic drag in cycling: methods of assessment. Sports Biomechanics. 10(3): 197-218.

12. de Groot G, Sargeant A, Geysel J. 1995. Air friction and rolling resistance during cycling. Medicine and Science in Sports and Exercise. 27: 1090-1095.

13. di Prampero PE, Cortili G, Mognoni P, Saibene F. 1979. Equation of motion of a cyclist. Journal of Applied Physiology. 47: 201-206.

14. DuBois D and DuBois E. 1916. A formula to estimate the approximate surface area if height and weight be known. Archives of Internal Medicine. 17: 863-871.

15. Edwards AG, Byrnes WC. 2007. Aerodynamic characteristics as determinants of the drafting effect in cycling. Medicine and Science in Sports and Exercise. 39(1): 170176.

16. Grappe F, Candau RB, Barbier B, Hoffman MD, Belli AR, Rouillon JD. 1999. Influence of tyre pressure and vertical load on coefficient of rolling resistance and simulated cycling performance. Ergonomics. 10: 1361-1371.

17. Grappe F, Candau RB, Belli AR, Rouillon JD. 1997. Aerodynamic drag in field cycling with special reference to the Obree's position. Ergonomics. 40: 1299-1311. 
18. Hawley JA, Noakes TD. 1992. Peak power output predicts maximal oxygen uptake and performance time in trained cyclists. European Journal of Applied Physiology and Occupational Physiology. 65: 79-83.

19. Heil DP. 2001. Body mass scaling of projected frontal area in competitive cyclists. European Journal of Applied Physiology. 85 (3-4): 358-366.

20. Heil DP. 2002. Body mass scaling of frontal area in competitive cyclists not using aero-handlebars. European Journal of Applied Physiology. 87: 520-528.

21. Hoogeveen AR Schep G. 1997. The plasma lactate response to exercise and endurance performance: relationships in elite triathletes. International Journal of Sports Medicine. 18: 526-530.

22. Jeukendrup AE, Martin J. 2001. Improving cycling performance: how should we spend our time and money. Sports Medicine. 31: 559-569.

23. Kyle CR. 1991. Wind tunnel tests of aero bicycles. Cycling Science. 3(3-4): 57-61. 24. Lamberts RP, Lambert MI, Swart J, Noakes TD. 2012. Allometric scaling of peak power output accurately predicts time trial performance and maximal oxygen consumption in trained cyclists. British Journal of Sports Medicine. 46(1): 36-41.

25. Lim AC, Homestead EP, Edwards AG, Carver TC, Kram R, Byrnes WC. 2011. Measuring changes in aerodynamic/rolling resistances by cycle-mounted power meters. Medicine and Science in Sports and Exercise. 43(5): 853-860.

26. Loftin M, Warren B. 1994. Comparison of a simulated 16.1-km time trial, VO2max and related factors in cyclists with different ventilatory thresholds. International Journal of Sports Medicine. 15: 498-503. 
27. Martin JC, Gardner AS, Barras M, Martin DT. 2006. Modelling sprint cycling using field-derived parameters and forward integration. Medicine and Science in Sports and Exercise. 38(3): 592-597.

28. Martin JC, Milliken DL, Cobb JE, McFadden KL, Coggan AR. 1998. Validation of a mathematical model for road cycling power. Journal of Applied Biomechanics. 14: 276-291.

29. McLean B. 1993. The relationship between frontal surface area and anthropometric parameters in racing cyclists. International Society of Biomechanics, XIVth Congress: July 4-8. Paris.

30. Nichols JF, Phares SL, Buono MJ. 1997. Relationship between blood lactate response to exercise and endurance performance in competitive female master cyclists. International Journal of Sports Medicine. 18: 458-463.

31. Olds T, Norton K, Craig N. 1993. Mathematical model of cycling performance. Journal of Applied Physiology. 75(2): 730-737.

32. Olds T, Norton K, Lowe E, Olive S, Reay F, Ly S. 1995. Modeling road-cycling performance. Journal of Applied Physiology. 78(4): 1596-1611.

33. Olds T, Olive S. 1999. Methodological considerations in the determination of projected frontal area in cyclists. Journal of Sports Science. 17: 335-345.

34. Pugh LG. 1974. The relation of oxygen intake and speed in competition cycling and comparative observations on the bicycle ergometer. Journal of Physiology. 241: 795808.

35. Smith JC, Dangelmaier BS, Hill DW. 1999. Critical power is related to cycling time trial performance. International Journal of Sports Medicine. 20: 374-378. 
1

The relationship between time trial performance time relative to non-normalized and normalized laboratory measures.

(A) Performance time relative to power at VO2 peak. (B) Performance time relative to power at lactate threshold (LT). (C) Performance time relative to power at VO2 peak normalized to field-determined drag area $\left(A_{d}\right)$. (D) Performance time relative to power at LT normalized to field-determined $A_{d}$. 

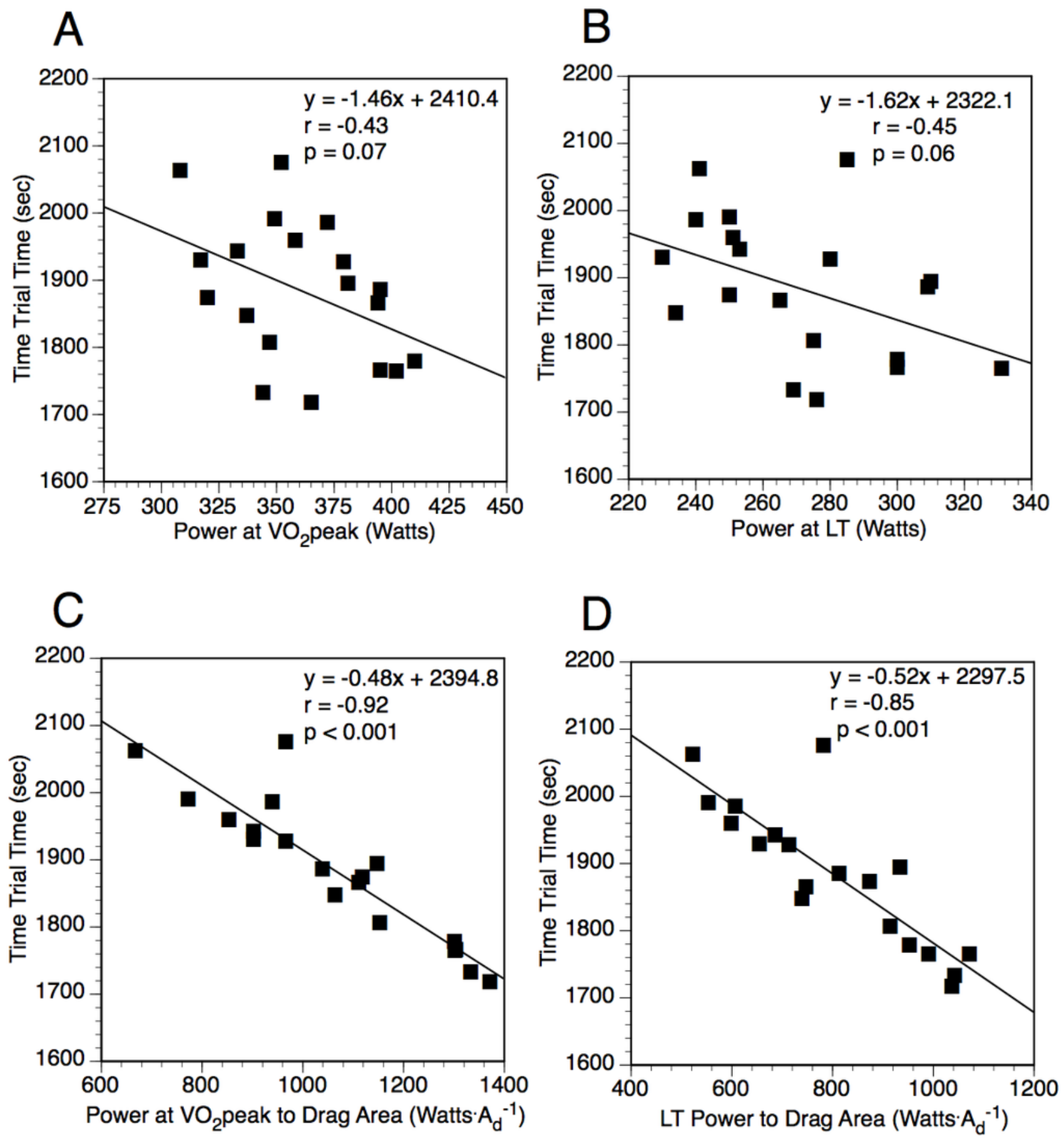
2

The relationship between time trial performance time relative to the non-normalized and normalized field-measured power output.

(A) Performance time relative to mean field-measured power output. (B) Performance time relative to mean field-measured power output normalized to body mass. (C) Performance time relative to mean field-measured power output normalized to frontal area $\left(A_{p}\right)$. (D) Performance time relative to mean fieldmeasured power output normalized to field-determined drag area $\left(A_{d}\right)$. 

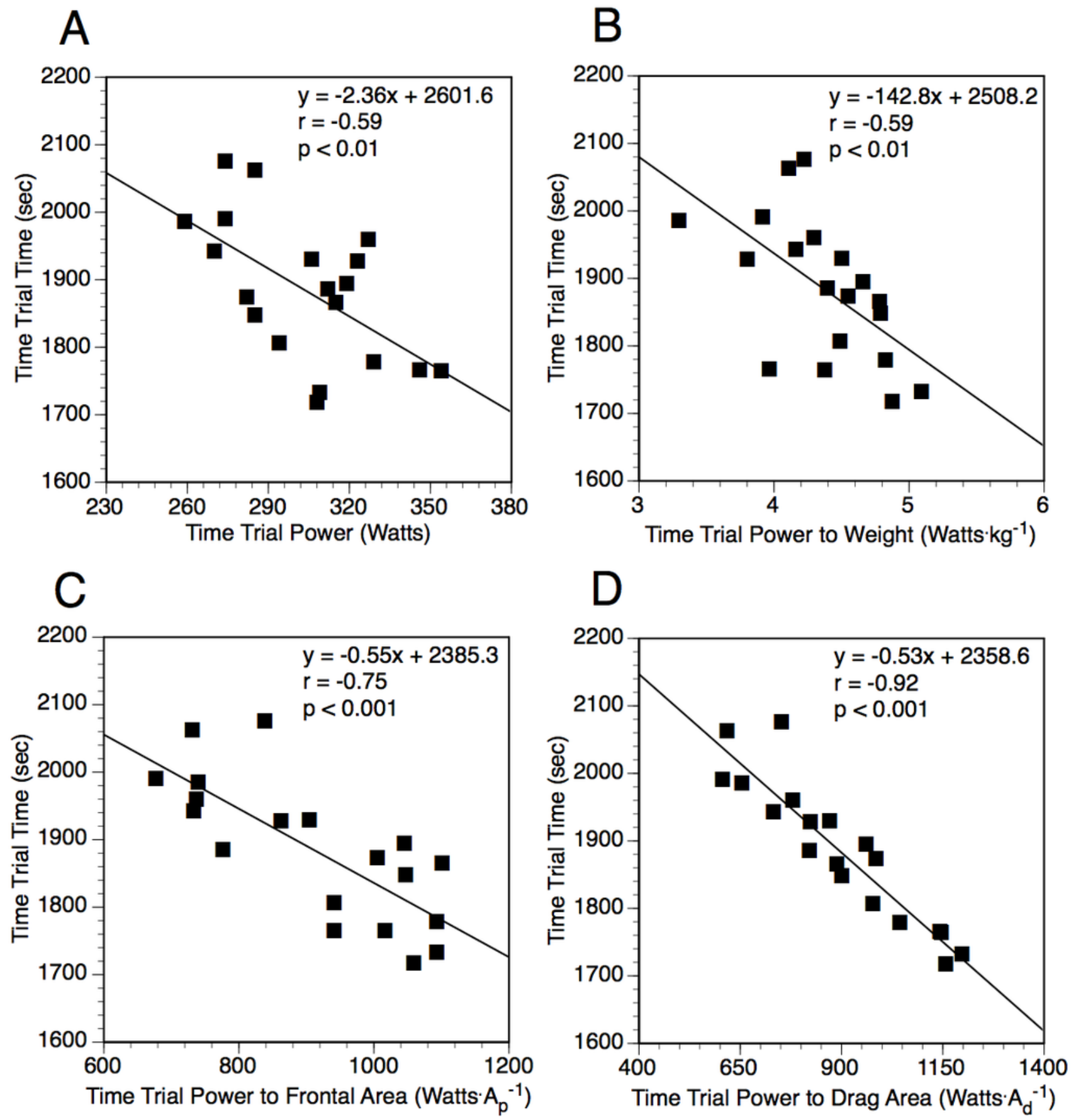


\section{Table $\mathbf{1}$ (on next page)}

Mean $\pm S D$, minimum, and maximum descriptive information for all 19 subjects and values for the primary physiological performance measures assessed during the laboratory graded exercise stress test. 


\begin{tabular}{|l|c|c|c|}
\hline & Mean \pm SD & Min & Max \\
\hline Age $($ years) & $27.6 \pm 4.6$ & 20 & 36 \\
\hline Height $(\mathrm{cm})$ & $174.0 \pm 6.0$ & 164 & 184 \\
\hline Body Mass $(\mathrm{kg})$ & $70.0 \pm 8.0$ & 59.5 & 87.3 \\
\hline Body Fat $(\%)$ & $10.4 \pm 2.64$ & 6.0 & 16.5 \\
\hline Bone Density $\left(\mathrm{g} \cdot \mathrm{cm}^{-2}\right)$ & $1.22 \pm 0.11$ & 1.03 & 1.41 \\
\hline Years Racing & $8 \pm 5$ & 3 & 20 \\
\hline $\mathrm{VO}_{2}$ peak $\left(1 \cdot \mathrm{min}^{-1}\right)$ & $4.67 \pm 0.40$ & 3.91 & 5.47 \\
\hline $\mathrm{VO}_{2}$ peak $\left(\mathrm{ml} \cdot \mathrm{kg}^{-1} \mathrm{~min}^{-1}\right)$ & $67.6 \pm 6.4$ & 54.2 & 76.5 \\
\hline Power at $\mathrm{VO}_{2}$ peak $(\mathrm{Watts})$ & $362 \pm 30$ & 308 & 410 \\
\hline Power to Mass at $\mathrm{VO}_{2}$ peak $\left(\mathrm{W} \cdot \mathrm{kg}^{-1}\right)$ & $5.15 \pm 0.51$ & 4.21 & 5.95 \\
\hline LT 1mM as \% of VO 2 peak & $76 \pm 4.5$ & 65 & 82 \\
\hline Power at LT $1 \mathrm{mM}(\mathrm{Watts})$ & $271 \pm 29$ & 230 & 331 \\
\hline Power to Mass at LT $1 \mathrm{mM}\left(\mathrm{W} \cdot \mathrm{kg}^{-1}\right)$ & $3.87 \pm 0.48$ & 3.03 & 4.53 \\
\hline Economy $\left(\mathrm{W} \cdot 1 \mathrm{O}_{2}^{-1}\right)$ & $73.5 \pm 3.1$ & 69.1 & 78.9 \\
\hline Max Heart Rate $(\mathrm{bpm})$ & $183 \pm 8$ & 168 & 197 \\
\hline
\end{tabular}


Table 2 (on next page)

Primary determinants of aerodynamic and rolling resistance measured on the bicycle and body position used during the time trial. 


\begin{tabular}{|l|c|c|c|}
\hline & Mean $\pm \mathrm{SD}$ & Min & Max \\
\hline Air Density $\left(\mathrm{kg} \cdot \mathrm{m}^{-3}\right)$ & $1.00 \pm 0.02$ & 0.98 & 1.05 \\
\hline $\mathrm{k}$ constant $\left(\mathrm{N} \cdot \mathrm{m}^{-2} \cdot \mathrm{s}^{2}\right)$ & $0.170 \pm 0.028$ & 0.126 & 0.228 \\
\hline $\mathrm{A}_{\mathrm{d}}\left(\mathrm{m}^{2}\right)$ & $0.349 \pm 0.059$ & 0.258 & 0.462 \\
\hline $\mathrm{A}_{\mathrm{P}}\left(\mathrm{m}^{2}\right)$ & $0.338 \pm 0.050$ & 0.272 & 0.444 \\
\hline Est $\mathrm{A}_{\mathrm{P}}\left(\mathrm{m}^{2}\right)($ Olds et al. & & & \\
$1995)$ & $0.342 \pm 0.017$ & 0.32 & 0.375 \\
\hline Est $\mathrm{A}_{\mathrm{P}}\left(\mathrm{m}^{2}\right)(\mathrm{Heil} 2002)$ & $0.327 \pm 0.027$ & 0.293 & 0.386 \\
\hline $\mathrm{R}_{\mathrm{r}}(\mathrm{N})$ & $4.88 \pm 1.27$ & 2.71 & 7.39 \\
\hline $\mathrm{C}_{\mathrm{r}}($ dimensionless $)$ & $0.006 \pm 0.002$ & 0.004 & 0.009 \\
\hline Total Mass $(\mathrm{kg})$ & $80.33 \pm 9.42$ & 68.9 & 99.7 \\
\hline
\end{tabular}

1

2 Constant $\mathrm{k}=$ aerodynamic character of a cyclist, $A_{d}=$ drag area, $A_{P}=$ measured projected

3 frontal area, Est $A_{P}=$ estimated projected frontal area, $R_{r}=$ rolling resistance, $C_{r}=$ quality of

4 the tire and road interface, and total mass = mass of bicycle and rider. 


\section{Table 3(on next page)}

Performance and environmental variables measured during the time trial. 


\begin{tabular}{|c|c|c|c|}
\hline & Mean \pm SD & Min & Max \\
\hline Total Time (min:sec) & $31: 24 \pm 2: 15$ & 28:05:00 & $34: 52: 00$ \\
\hline Temperature $\left({ }^{\circ} \mathrm{C}\right)$ & $26.2 \pm 4.5$ & 20 & 35 \\
\hline Humidity (\%) & $30.7 \pm 9.5$ & 14 & 50 \\
\hline Air Pressure $(\mathrm{mmHg})$ & $629.2 \pm 3.7$ & 626.4 & 638.3 \\
\hline Air Density $\left(\mathrm{kg} \cdot \mathrm{m}^{-3}\right)$ & $0.97 \pm 0.02$ & 0.95 & 1 \\
\hline Average Power (Watts) & $303 \pm 26$ & 259 & 354 \\
\hline $\begin{array}{l}\text { Standard Deviation of the } \\
\text { Power During the Time } \\
\text { Trial (Watts) }\end{array}$ & $80 \pm 14$ & 61 & 113 \\
\hline Power (Watts $\cdot \mathrm{kg}^{-1}$ ) & $4.32 \pm 0.44$ & 3.27 & 4.98 \\
\hline Power (\% of LT) & $112.4 \pm 9.2$ & 96.1 & 133 \\
\hline Power ( $\%$ of $\mathrm{VO}_{2}$ peak $)$ & $84.1 \pm 5.9$ & 69.6 & 92.5 \\
\hline Heart Rate (bpm) & $173 \pm 6$ & 161 & 183 \\
\hline $\begin{array}{l}\text { Standard Deviation of the } \\
\text { Heart Rate During the Time } \\
\text { Trial (bpm) }\end{array}$ & $8 \pm 2$ & 4 & 11 \\
\hline Heart Rate ( $\%$ of LT HR) & $111.9 \pm 3.8$ & 101.5 & 117.6 \\
\hline Heart Rate $\left(\%\right.$ of Max $\left.\mathrm{HR}_{\mathrm{r}}\right)$ & $95.5 \pm 1.1$ & 93.3 & 96.8 \\
\hline $\begin{array}{l}\text { Max Heart Rate During the } \\
\text { Time Trial (bpm) }\end{array}$ & $180 \pm 6.3$ & 167 & 192 \\
\hline
\end{tabular}

